\title{
Size and spatio-temporal variations of the Andean condor Vultur gryphus population in north-west Patagonia, Argentina: communal roosts and conservation
}

SERGio A. LA M B ERTUCCI

\begin{abstract}
Estimations of the population sizes of threatened species are fundamental for conservation. The current estimate of the population of the Andean condor Vultur gryphus is based on limited local counts. Simultaneous censuses of 10 condor communal roosts were therefore conducted during 2006-2008 in north-west Patagonia, Argentina, to obtain a minimum population number, to estimate the size of the local population, and to describe use of the roosts by season and age classes. I fitted the data to two asymptotic models to calculate the population of condors as a function of the number of communal roosts surveyed. In an area of c. $6,300 \mathrm{~km}^{2}$ I obtained a minimum population size of 246 individuals by direct observation, and a population estimate of 296 condors (range 260-332) by applying the models. This population, the largest known of this species, comprises $68.5 \%$ adults and $31.5 \%$ immatures. Condors had large aggregations in some communal roosts and used the area seasonally, increasing in numbers from autumn to spring and decreasing in summer. Longterm monitoring of communal roosts across the Andean condor's range is essential for the monitoring of this rare and vulnerable species.
\end{abstract}

Keywords Accumulation curves, age-class proportion, Andean condor, Argentina, Patagonia, population size, roost, Vultur gryphus

\section{Introduction}

pecies conservation and management decisions require $\checkmark$ information on population size, a parameter that is difficult to obtain for species that are rare, elusive or that inhabit places that are difficult for researchers to reach. To compare population numbers over time, and to detect trends effectively, systematic monitoring studies are required. Such monitoring is also useful for the development of conservation and management plans (Butchart et al., 2006). Monitoring is particularly important for large scavenging raptors, several species of which are rare and

Sergio A. LAmbertucci Laboratorio Ecotono, Centro Regional Universitario Bariloche, Universidad Nacional del Comahue, INIBIOMA-CONICET, Quintral 1250, Bariloche, Argentina. E-mail slambertucci@crub.uncoma.edu.ar

Received 15 January 2009. Revision requested 20 April 2009.

Accepted 28 May 2009. declining (Ferguson-Lees \& Christie, 2001). These birds are at the top of the food chain, have low reproductive rates, and their populations typically have a high percentage of non-reproductive birds, making the species susceptible to extinction from human persecution (Meretsky et al., 2000; Owens \& Bennett, 2000; Ferguson-Lees \& Christie, 2001).

Scavengers such as vultures are exposed to several critical threats (Koenig, 2006). In Africa, for example, vultures are unintended victims of poisoned carcasses laid out for other carnivores (Brown, 1991; Koenig, 2006). Residues of diclofenac, an anti-inflammatory drug used for livestock in Asia, have brought the populations of three vulture species close to extinction (Oaks et al., 2004). California condors Gymnogyps californianus are threatened by lead poisoning in North America (Meretsky et al., 2000), and lead and other poisons are threatening vultures in Europe (e.g. Donázar et al., 2002) and condors in South America (Díaz et al., 2000; Lambertucci, 2007). Knowledge of the population size and age class structure of these species is required for estimating future viability.

The Andean condor Vultur gryphus is distributed throughout the Andes in South America, from Venezuela to southern Argentina and Chile. It is categorized as Near Threatened on the IUCN Red List, listed in Appendix I of CITES and is extinct in some parts of its range (BirdLife International, 2008). It is a long-lived species with one of the lowest reproductive rates among birds (Wallace \& Temple, 1988; Lambertucci, 2007). Continuing declines have been documented in some areas where the species is already disappearing or scarce (Calchi \& Viloria, 1991; Lieberman et al., 1993; Koenen et al., 2000) but little is known about population sizes and trends in areas where the species is more abundant. Local population estimates are available for Peru (109 individuals; Wallace \& Temple, 1988), Bolivia (78; Ríos-Uzeda \& Wallace, 2007), central Argentina (100; Donázar \& Feijóo, 2002), southern Argentina (196; Lambertucci et al., 2008) and southern Chile (73; Kusch, 2004). The northern population has been estimated to be c. 200, from northern Ecuador to Venezuela (Díaz et al., 200o). Díaz et al. (2000) proposed a figure of 6,200 individuals for the species but this estimate was based on data from only a few sites.

Condors breed solitarily but roost and eat communally (del Hoyo et al., 1994; Lambertucci, 2007). Although the use of communal roosts is variable across days, seasons and 
years, they are good places to estimate abundance (Kusch, 2004; Lambertucci et al., 2008). The aims of the study reported here were to derive minimum population numbers for condors in north-western Patagonia, to estimate the size of the local population, and to describe the use of the roosts by season and age classes. The estimates are a reference for future studies requiring data on population size and trends of the Andean condor and other large scavengers.

\section{Study area}

I selected the 10 main Andean condor communal roosts within an area of c. $6,300 \mathrm{~km}^{2}$ in north-western Patagonia,
Argentina (Fig. 1). The area encompasses a mosaic of woodlands and steppes, used mainly for extensive livestock ranching and where there are increasing numbers of introduced mammals (red deer Cervus elaphus, wild boar Sus scrofa and European hare Lepus europaeus). Carcasses consumed by condors are thus abundant throughout the study area (Lambertucci et al., 2009b). The climate of the region is cool temperate, with precipitation mainly concentrated in winter and autumn, and with summer being the driest season (Paruelo et al., 1998). The area's geological history, along with more recent erosive processes, has created numerous cliffs that are used by the Andean condor for roosting and breeding.

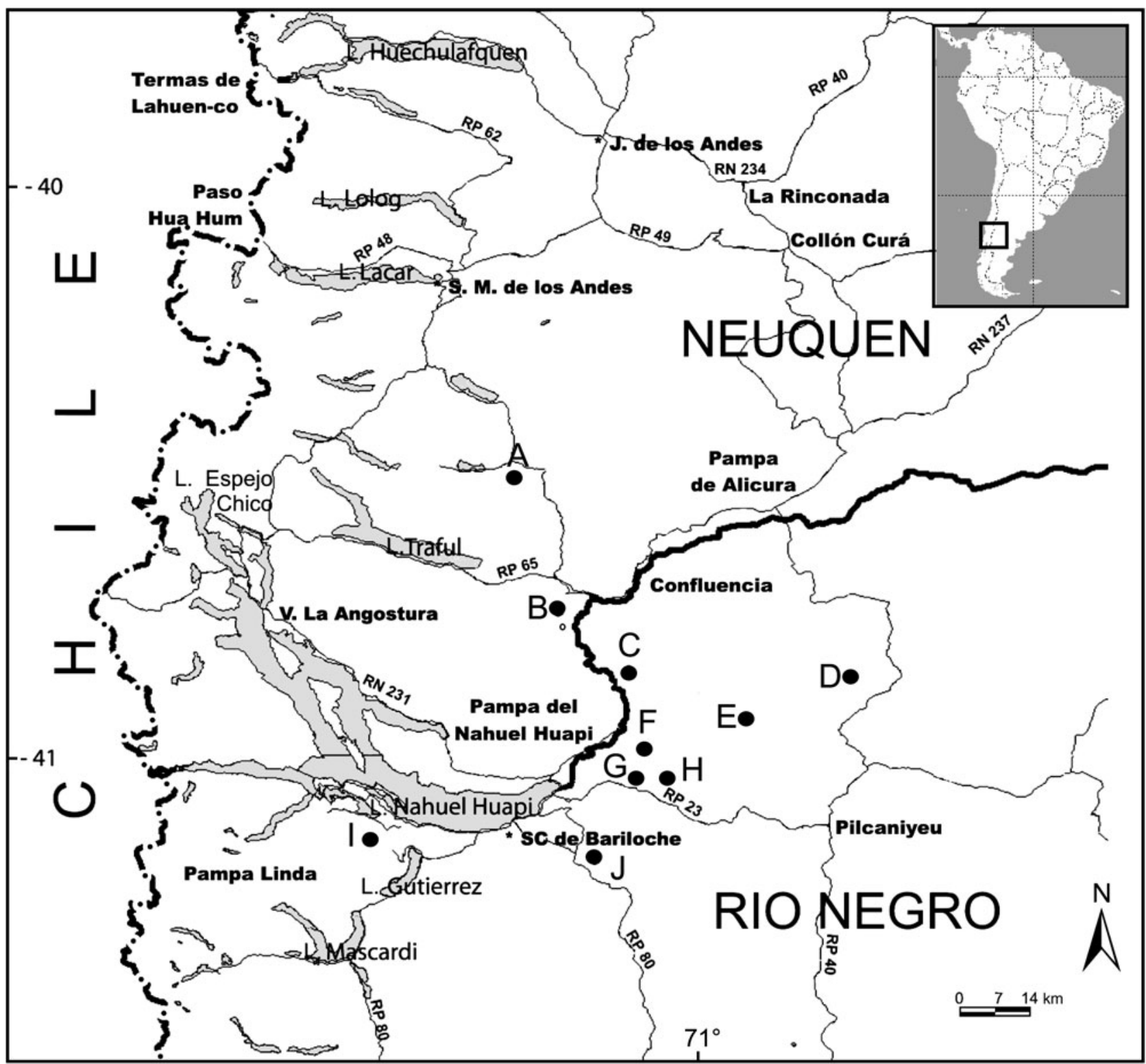

FIG. 1 Locations of the 10 communal roosts (A-J) of the Andean condor Vultur gryphus surveyed in north-west Patagonia, Argentina. Inset indicates the location of the main figure in South America. 


\section{Methods}

\section{Survey}

Two or three trained observers visited each of the 10 communal roosts on 15 occasions from January 2006 to December 2008 to count the condors from blinds $(>300 \mathrm{~m}$ from the roost) with the aid of telescopes $(20-60 \times 60)$ and binoculars $(10 \times 50)$. Roosts were surveyed simultaneously (i.e. a team of $20-30$ observers surveyed all 10 roosts on the same days) to avoid counting the same bird more than once and because there can be strong daily variations in the use of the communal roosts (Lambertucci et al., 2008). Condors at each roost were counted twice: a last-light census at dusk, at the time when the observers could still distinctly see individual condors, to coincide with the time when the majority of the condors were roosting and only a minority, or none, were flying, and a first-light census the following morning, before the condors left the roost, to verify the number of individuals counted the previous night. I used the larger of the two counts as the abundance of condors roosting. Condors were classified as immature (juveniles, brown without a collar, and subadults, brown-grey with a white collar) or adult (black with white coverts on the upper wing and a white collar; McGahan, 1972; del Hoyo et al., 1994).

\section{Data analysis}

To analyse the number of condors in relation to the number of communal roosts, I constructed two accumulation curves from the complete set of censuses. These curves comprise a simple and reliable method used in biodiversity studies to estimate the number of species in a certain area (Soberón \& Llorente, 1993). As the sampling effort increases new species are added at a decreasing rate until an asymptote is reached. Application of accumulation curves facilitates estimation of how many communal roosts must be surveyed to census a high proportion (e.g. $>80 \%$ ) of a population. They also allow comparison of abundances in different parts of a species' range. For the whole set of censuses I selected the communal roost with the highest number of individuals and then progressively added the combination of sites with the next highest number of individuals, and so on. To calculate the population of Andean condors in the area I fitted the data to the two asymptotic models, Clench's, $S n=a n /(1+b n)$, and the exponential model, $S n=a / b[1-\exp (-b n)]$. In both models $S n$ is the expected size in the number of species (in this case number of individuals), $a$ is the initial slope, $b$ is a parameter related to the shape of the curve, and $n$ is the sampling effort (in this case the number of communal roosts surveyed). The asymptote represents the total number of individuals predicted by the function, and is given by $a / b$ (Soberón $\&$ Llorente, 1993). Clench's model is recommended for large sampling areas and has a good fit to real situations, whereas the exponential function is recommended when the area is smaller or all individuals have a high probability of being found (Soberón \& Llorente, 1993; Moreno \& Halffter, 2000). I considered that the exponential model would predict the lower limit whereas Clench's model would provide an upper limit, with the true accumulation curve of individuals lying between them (Moreno \& Halffter, 2000). Therefore, I calculated the intermediate value between the asymptotes as an estimate of the number of individuals in the area.

On nine occasions I included other, smaller-sized, communal roosts (between one and four) to check that the use of the chosen 10 roosts accounted for a large proportion of the population. Using these further roosts I never obtained more individuals than in the maximum counts from the 10 selected roosts. I examined possible differences in condor abundances among seasons and age classes using an ANOVA, $t$-test, and $\chi^{2}$ tests and a significance level of $\mathrm{P} \leq 0.05$.

\section{Results}

The maximum number of condors counted simultaneously in the 10 communal roosts was 246 . However, the variability of the data was large (range $=27-246$; Fig. 2 ). There was a strong seasonal use of the roosts, mainly because condors do not aggregate strongly in this area during summer

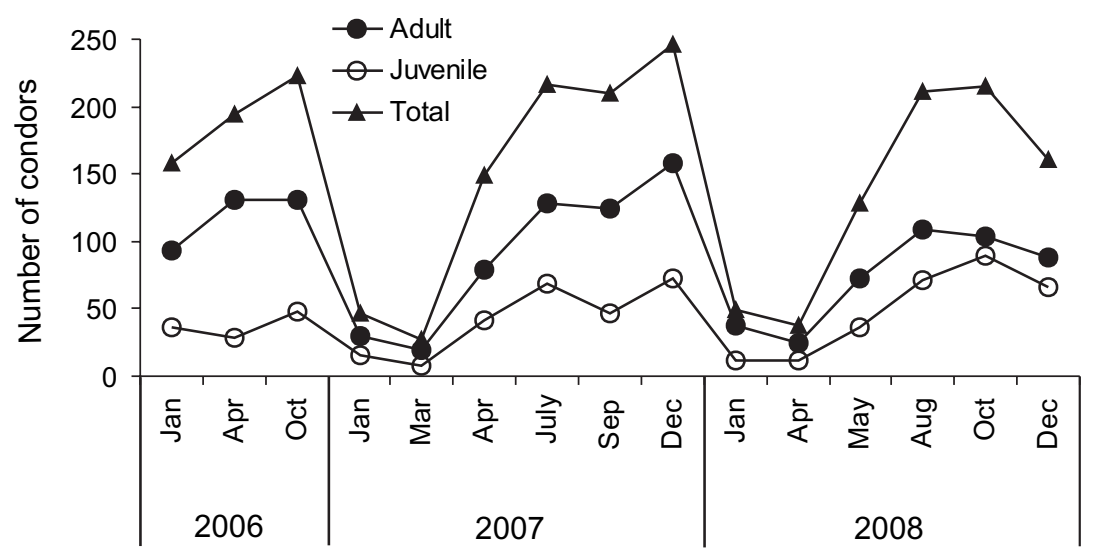

Fig. 2 Temporal trends in the numbers of Andean condors observed during 20062008 at 10 communal roosts (Fig. 1) surveyed simultaneously in north-west Patagonia, Argentina. 
(Fig. 2). The maximum numbers of condors did not differ among years $\left(\chi_{2}^{2}=2.27, \mathrm{P}=0.32\right)$ but there were clear seasonal differences in the use of the area (Fig. 2, ANOVA $\left.F_{3,11}=7.23, \mathrm{P}=0.006\right)$. The main differences were between summer, and winter and spring (Tukey test, $P_{\text {summer-winter }}=$ 0.03 ; $\left.P_{\text {summer-spring }}<0.01\right)$. However, each roost varied in the month in which the number of individuals peaked (Fig. 3). Some seemed to be used more in autumn (Fig. 3A,C,J), others in spring (Fig. $3 \mathrm{~B}, \mathrm{D}, \mathrm{F}, \mathrm{G}$ ) and/or in winter (Fig. 3E,H,I,J).

I observed more adults than immatures in the area yearround ( $t=3.39, \mathrm{df}=28, \mathrm{P}<0.01$; Fig. 2 ), with a maximum of 159 adults (68.5\%) and 73 immatures (31.5\%) for the same year (2007). The maximum number of immatures was 89 during December 2008. The ratio of adults to immatures, based on the maximum number of each age class counted simultaneously, was strongly biased toward adults ( $1: 0.46)$. Although both age classes used the same area synchronously (Fig. 2) there were differences in monthly use, which varied between roosts (Fig. 3).

Both of the applied accumulation models fitted the observed data well $\left(r^{2}>0.97\right.$; Table 1, Fig. 4). As expected, I obtained a larger population estimate with Clench's function than with the exponential model (Fig. 4). The intermediate value between the asymptotes of the two models was 296.
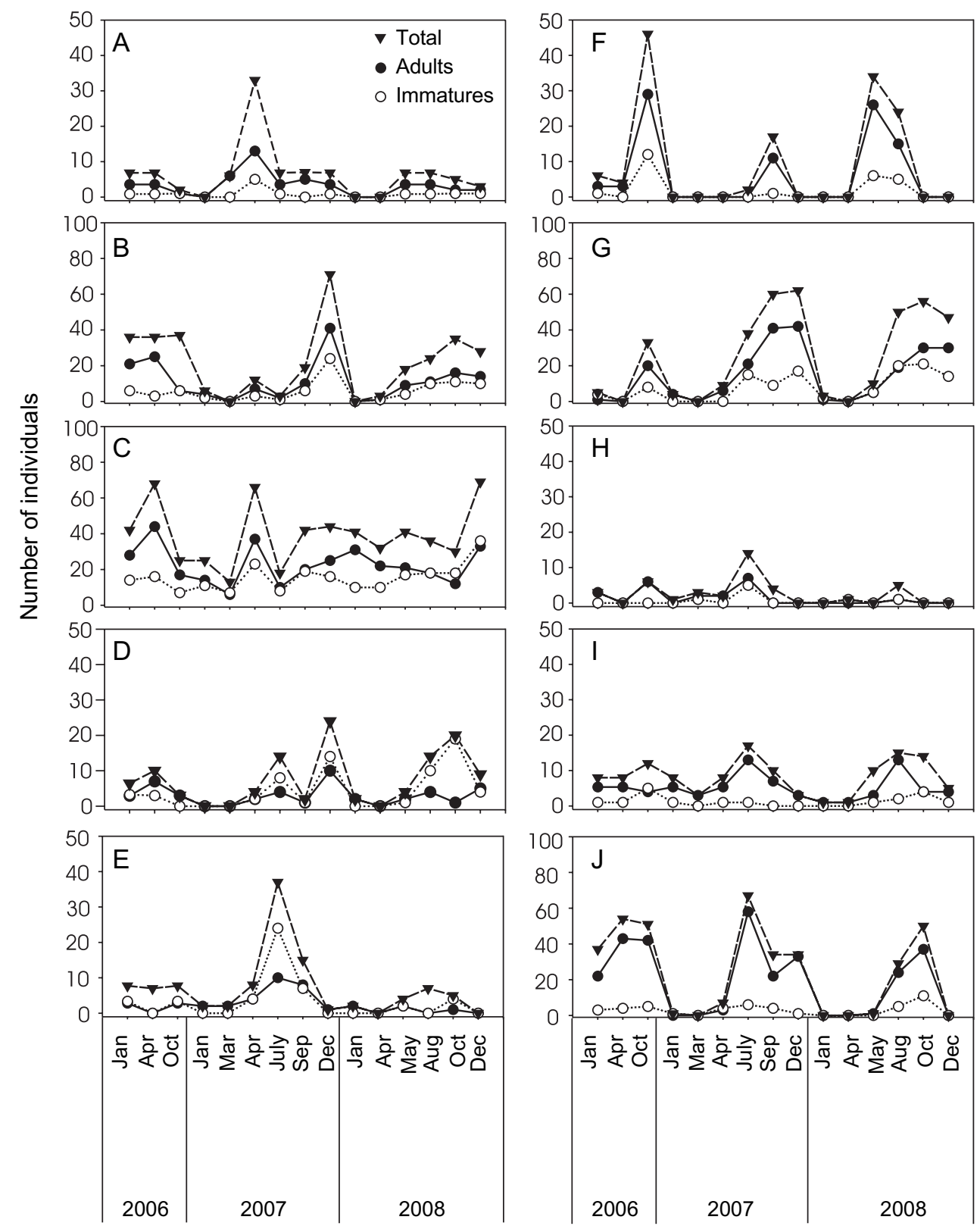

Fig. 3 Temporal trends in the numbers of Andean condors observed at each of the 10 communal roosts (A-J, Fig. 1) surveyed simultaneously during 2006-2008 in north-west Patagonia, Argentina. Note the differing y-axis scales. 


\section{Discussion}

The Andean condor population of north-west Patagonia is the most important known for the species. Minimum and estimated population sizes are 246 and 296 (range 260-332), respectively, in an area of c. $6,300 \mathrm{~km}^{2}$. Of the estimated total population of 6,200 (Díaz et al., 2000) this population comprises c. $4.8 \%$. In the same region 136 condors have previously aggregated in just one communal roost, and up to 196 in three roosts during 2001 (Lambertucci et al., 2008). Explanations for communal roosting in such large groups may include, for example, social interaction, a climate effect, and food and space availability (Beauchamp, 1999; Lambertucci, 2007).

My estimate of the population may be conservative as it does not account for condors breeding away from the communal roosts or for fledglings that remain in the nest for several months (Lambertucci \& Mastrantuoni, 2008). In addition, this population could be an open one that uses an area larger than that surveyed. The Andean condor's home range has not been fully studied but five satellite tagged juvenile condors from the same area flew almost $600 \mathrm{~km}$ north-south and $100 \mathrm{~km}$ west-east, and almost $200 \mathrm{~km}$ in one day (Astore, 2001; L. Jácome pers. comm.). However, counting condors in different communal roosts simultaneously, as in the present work, avoids counting an individual more than once per census and provides estimates of the minimum and total population of an area. Application of this type of census across the species' range will allow comparisons between populations. Satellite tagging or newer techniques (e.g. Wilson et al., 2008) could provide information on the species' home range and on the time condors dedicate to communal roosting.

During the 3-year study the abundance of condors was stable, although birds used the region with a clear seasonality, increasing from autumn to spring and decreasing in summer. The Egyptian vulture Neophron percnopterus has a similar pattern in Europe coinciding with its breeding season (Donázar et al., 2002). Breeding is unlikely to be the main reason for the seasonal movements of condors, as the breeding season extends throughout the year (Lambertucci \& Mastrantuoni, 2008). In this study I included almost all of the communal roosts in the study area and therefore it appears that condors move away from the study area, mainly during the summer. Because the main movements are latitudinal (Astore, 2001) condors could, for example, be following livestock movements initiated by farmers during summer, be moving to areas with better weather and flying conditions, or be dispersing to areas less accessible to researchers.

Knowledge of age structure and sex ratio is important for demographic studies (Ezard et al., 2006). In north-west Patagonia $68.5 \%$ of the individuals were adults and therefore c. 200 adult condors may potentially breed. However, given that, even during favourable conditions, condors can only nest up to once every other year (del Hoyo et al., 1994; Lambertucci \& Mastrantuoni, 2008), a maximum of 100 may breed each year if the male to female ratio is $1: 1$. If this is the case (although it is probably not; M. Alcaide, L. Cadahía, S.A. Lambertucci \& J.J Negro, unpubl. data), this population could produce c. 50 chicks per year. The ratio of adults to immatures of $1: 0.46$ in this population is similar to that in southern Chile (1:0.52; Sarno et al., 2000), and Peru (1:0.35; Wallace \& Temple, 1988) but different from that in Bolivia (1:1.5; Ríos-Uzeda \& Wallace, 2007). It has been proposed that the adult:immature proportion may indicate the reproductive rate of the Andean condor (Wallace \& Temple, 1988). However, a skewed adult:immature ratio could be because of the condors' long life-span, low reproductive rate and low natural mortality rate. The ratio could also be influenced by differences in age-class habitat use (Donázar et al., 1999; Sarno et al., 2000).

The Andean condor was formerly more widely distributed, including in eastern South America (Lambertucci, 2007). However, no historic estimations for abundance exist for the entire range. The number of individuals found in this study, although the highest concentration known, is low compared to related species (Ferguson-Lees \& Christie, 2001). The griffon vulture Gyps fulvus in southern Spain, where it feeds on extensively raised livestock, can reach c. 1,500 pairs in c. $8,000 \mathrm{~km}^{2}$ (Del Moral \& Martí, 2001; J. Donázar, pers. comm.). My maximum estimate was c. 300 individuals ( 200 adults) in c. $6,200 \mathrm{~km}^{2}$. Given that food is abundant and human density is low in Patagonia, Andean condors may maintain low densities in the area because of threats such as persecution, poisoning and electrocution (Lambertucci, 2007). The low number of individuals could otherwise indicate that Andean condors are habitually rare. Notwithstanding, both possibilities make this a species of conservation concern.

TABLE 1 Estimates of the Andean condor Vultur gryphus population in north-west Patagonia obtained by fitting two asymptotic accumulation models. In both models $a$ is the slope at the beginning of the sampling, $b$ is a parameter related to the shape of the curve, $n$ is the sampling effort, $a / b$ is the asymptote of the curve and represents the total population, $R^{2}$ is the proportion of variance accounted for each model, and $\mathrm{CI}$ is the confidence interval.

\begin{tabular}{llll}
\hline Method & $\mathrm{R}^{2}$ & $\mathrm{a} \pm \mathrm{CI}$ & $\mathrm{b} \pm \mathrm{CI}$ \\
\hline Clench's model $(S n=a n /(1+b n))$ & 0.979 & $123.707 \pm 34.053$ & $0.372 \pm 0.1472$ \\
Exponential model $(S n=a / b[1-\exp (-b n)])$ & 0.991 & $100.383 \pm 12.016$ & $0.386 \pm 0.061$ \\
\hline
\end{tabular}




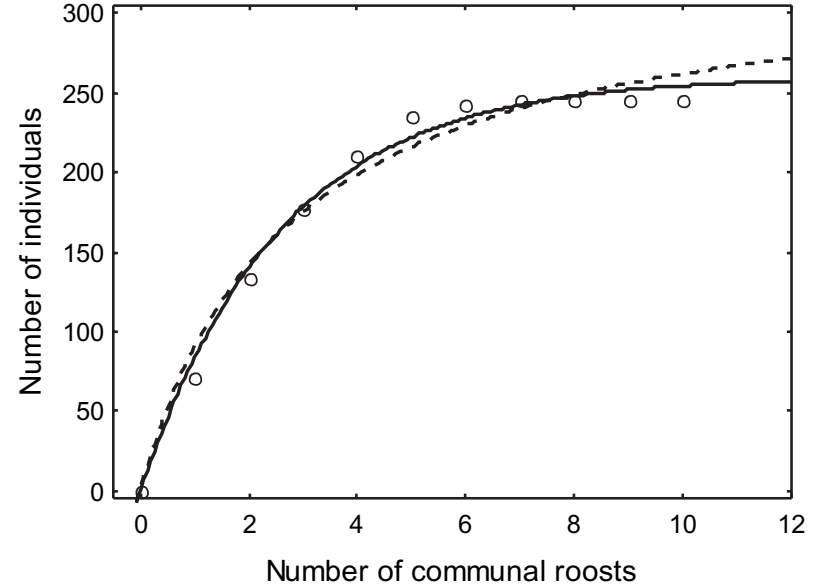

FIG. 4 Observations (circles) and fitted accumulation curves (lines) for the maximum number of condors in 1-10 communal roosts surveyed simultaneously. Two asymptotic models (Table 1), Clench's (dashed line) and the exponential (solid line), are fitted to estimate the increment in the number of individuals in relation to the increment in the area surveyed.

The design of any protected areas for the Andean condor should include not one but a set of communal roosts used by different age classes and at different times of the year. However, considering the wide range of this species, it is also necessary to consider problems such as poisoning and hunting pressure. For instance, condors can aggregate around a carcass in groups of c. 30 in this area (Speziale et al., 2008; Lambertucci et al., 2009a; S.A. Lambertucci, pers. obs.). Thus, just 10 poisoned carcasses could extinguish the population. It is important to identify any new communal roosts and to obtain population estimations of the Andean condor for the whole of South America. Long-term monitoring is essential for the detection of potential declines, which could then be addressed before they become critical.

\section{Acknowledgements}

I am especially grateful to volunteers and coordinators from Global Vision International, and also to F. Barbar, O. Mastrantuoni, H. Pastore, V. Werenkraut, J. Benclowicz, C. Lambertucci and K.L. Speziale for help in the field. J.A. Donázar, A. Ruggiero, C. Wells, T. Rogers, J. Jones, K.L. Speziale, R. Wilson and two anonymous reviewers provided valuable suggestions that improved this article. Managers and owners of La Buitrera del Ñirihuau, San Ramón, Siete Cóndores, Pilcañeu, Chacabuco, Cerro López, La Lonja and Cerro Negro farms as well as the Argentinean National Park Administration gave permission to study the roosts. SAL was funded from the CONICET, ANPCYT (PICT 38148) and Universidad Nacional del Comahue during this work.

\section{References}

Astore, V. (2001) Estudio de la capacidad de vuelo del Cóndor Andino (Vultur gryphus) en Patagonia Argentina, y análisis comparativo de metodologías utilizadas para su seguimiento a campo en Sudamérica. Seminario de Licenciatura, Universidad CAECE, Buenos Aires, Argentina.

BeAuchamp, G. (1999) The evolution of communal roosting in birds: origin and secondary losses. Behavioral Ecology, 6, 675-687.

BirdLife International (2008) Vultur gryphus. In IUCN Red List of Threatened Species v. 2010.1. Http://www.iucnredlist.org [accessed 18 March 2010].

Brown, C.J. (1991) An investigation into the decline of the bearded vulture Gypaetus barbatus in Southern Africa. Biological Conservation, 57, 315-337.

Butchart, H.M., Stattersfield, A.J. \& Collar, N.J. (2006) How many bird extinctions have we prevented? Oryx, 40, 266-278.

Calchi, R. \& Viloria, A.L. (1991) Occurrence of the Andean condor in the Perijá Mountains of Venezuela. Wilson Bulletin, 103, $720-722$.

del Hoyo, J., Elliott, A. \& Sargatal, J. (1994) Handbook of the Birds of the World, Volume 2. New World Vultures to Guineafowl. Lynx Edicions, Barcelona, Spain.

Del Moral, J.C. \& Martí, R. (eds) (2001) El Buitre Leonado en la Península Ibérica, III Censo Nacional y I Censo Ibérico coordinado, 1999. Monografía no. 7. SEO/BirdLife, Madrid, Spain.

Díaz, D., Cuesta, M., Abreu, T. \& Mujica, E. (2000) Estrategia de conservación para el cóndor andino (Vultur gryphus). WWF and Fundación BioAndina, Caracas, Venezuela.

Donázar, J.A. \& Feijóo, J.E. (2002) Social structure of Andean condor roosts: influence of sex, age, and season. Condor, 104, 832-837.

Donázar, J.A., Palacios, C.J., Gangoso, L., Ceballos, O., GonzÁlez, M.J. \& Hiraldo, F. (2002) Conservation status and limiting factors in the endangered population of Egyptian vulture (Neophron percnopterus) in the Canary Islands. Biological Conservation, 107, 89-97.

Donázar, J.A., Travaini, A., Ceballos, O., Rodríguez, A., Delibes, M. \& Hiraldo, F. (1999) Effects of sex-associated competitive asymmetries on foraging group structure and despotic distribution in Andean condors. Behavioral Ecology and Sociobiology, 45, 55-65.

Ezard, T.H.G., Becker, P.H. \& Coulson, T. (2006) The contributions of age and sex to variation in common tern population growth rate. Journal of Animal Ecology, 75, 1379-1386.

Ferguson-Lees, J. \& Christie, D.A. (2001) Raptors of the World. Christopher Helm, London, UK.

Koenen, M.T., Koenen, S.G. \& Yanez, N. (2000) An evaluation of the Andean condor population in northern Ecuador. Journal of Raptor Research, 34, 33-36.

Koenig, R. (2006) Vulture research soars as the scavengers' numbers decline. Science, 312, 1591-1592.

Kusch, A. (2004) Distribución y uso de dormideros por el cóndor Andino (Vultur gryphus) en Patagonia Chilena. Ornitología Neotropical, 15, 313-317.

LAMBertuCCI, S.A. (2007) Biología y conservación del Cóndor Andino (Vultur gryphus) en Argentina. Hornero, 22, 149-158.

Lambertucci, S.A., Jácome, N.L. \& Trejo, A. (2008) Use of communal roosts by Andean condors in northwest Patagonia, Argentina. Journal of Field Ornithology, 79, 138-146.

Lambertucci, S.A. \& Mastrantuoni, O.A. (2008) Breeding behavior of a pair of free-living Andean condors. Journal of Field Ornithology, 79, 147-151. 
Lambertucci, S.A., Speziale, K.L., Rogers, T.E. \& Morales, J.M. (2009a) How do roads affect the habitat use of an assemblage of scavenging raptors? Biodiversity and Conservation, 18, 2063-2074.

Lambertucci, S.A., Trejo, A., Di Martino, S., SánchezZapata, J.A., Donázar, J.A. \& Hiraldo, F. (2009b) Spatial and temporal patterns in the diet of the Andean condor: ecological replacement of native fauna by exotic species. Animal Conservation, 12, 338-345.

Lieberman, A., Rodriguez, J.V., Paez, J.M. \& Wiley, J. (1993) The reintroduction of the Andean condor into Colombia, South America: 1989-1991. Oryx, 27, 83-90.

McGahan, J. (1972) Behavior and ecology of the Andean condor. $\mathrm{PhD}$ thesis, University of Wisconsin, Madison, USA.

Meretsky, V.J., Snyder, N.F.R., Beissinger, S.R., Clendenen, D.A. \& Wiley, J.W. (2000) Demography of the California condor: implications for reestablishment. Conservation Biology, 14, $957-967$.

Moreno, C.E. \& Halffter, G. (2000) Assessing the completeness of bat biodiversity inventories using species accumulation curves. Journal of Applied Ecology, 37, 149-158.

Oaks, J.L., Gilbert, M., Virani, M.Z., Watson, R.T., Meteyer, C.U., Rideout, B.A. et al. (2004) Diclofenac residues as the cause of vulture population decline in Pakistan. Nature, 427, 630-633.

OWEns, I.P.F. \& BenNett, P.M. (2000) Ecological basis of extinction risk in birds: habitat loss versus human persecution and introduced predators. Proceedings of the National Academy of Sciences of the USA, 97, 12144-12148.

Paruelo, J.M., Beltrán, A., Jobbágy, E., Sala, O.E. \& Golluscio, R.A. (1998) The climate of Patagonia: general patterns and controls on biotic processes. Ecología Austral, 8, $85-101$.

Ríos-Uzeda, B. \& Wallace, R.B. (2007) Estimating the size of the Andean condor population in the Apolobamba Mountains of Bolivia. Journal of Field Ornithology, 78, 170-175.

Sarno, R.J., Franklin, W.L. \& Prexl, W.S. (2000) Activity and population characteristics of Andean condor in southern Chile. Revista Chilena de Historia Natural, 73, 3-8.

Soberón, J.M. \& Llorente, J.B. (1993) The use of species accumulation functions for the prediction of species richness. Conservation Biology, 7, 480-488.

Speziale, K.L., Lambertucci, S.A. \& Olsson, O. (2008) Disturbance from roads negatively affects Andean condor habitat use. Biological Conservation, 141, 1765-1772.

Wallace, M.P. \& Temple, S.A. (1988) Impacts of the 1982-1983 El Niño on population dynamics of Andean condors in Peru. Biotropica, 20, 144-150.

Wilson, R.P., Shepard, E.L.C. \& Liebsch, N. (2008) Prying into the intimate details of animal lives: use of a daily diary on animals. Endangered Species Research, 4, 123-137.

\section{Biographical sketch}

Sergio A. Lambertucci's main interests are animal ecology and conservation, with a particular focus on the ecology, biodiversity and behaviour of raptors. He has worked on the ecology and conservation of the Andean condor in Patagonia for more than a decade. 